\title{
Changes in the normal range of thyroidal radioiodine uptake
}

\author{
D. H. KEELING AND E. S. WILLIAMS \\ From the Institute of Nuclear Medicine, The Middlesex Hospital Medical School, London
}

SYNOPSIS Three series of patients shown to be euthyroid but originally referred for thyroid uptake tests in vivo have been compared.

In $1958-59$, the 'normal' mean thyroid uptake was $23.5 \%$ and $38.2 \%$ respectively at four and 24 hours. By 1967, the mean uptakes had dropped to $20.4 \%$ and $31.6 \%$-a significant change at both times. By 1972 there was, however, no sign of a further reduction of the mean normal values for thyroid uptake.

These results are compared with changes observed in other series in the USA and elsewhere.

In spite of several newer routine tests of thyroid function, two well established ones are still the most widely used. They are the measurement of the serum concentration of protein-bound iodine (PBI) and the measurement of the radioiodine accumulation in the thyroid in a specified time, the 'thyroid uptake'. These tests are very familiar and hence there is a danger of established reference material continuing in use long after it should have been revised. This paper draws particular attention to the need for keeping thyroid uptake normal ranges under review, although it should be noted that the PBI can also provide misleading results from the same causes (Acland, 1971).

It is well known that normal ranges of thyroid uptake vary from one community to another, depending upon the amount of iodide available from the diet (Oddie and Fisher, 1967; Forcher, Lanaro, Enriori, and Reforzo-Membrives, 1971). Provided habits do not change then test results can be compared with the appropriate established range. Unfortunately in the technically advanced nations there is often a marked lack of uniformity, usually an increase in iodide intake for some individuals, so that tracer test results in vivo can be misleading. Although it was at one time thought that an intake of $200 \mathrm{mg}$ of potassium iodide (about $150 \mathrm{mg} \mathrm{I})$ was necessary to reduce tracer uptake to zero (Pochin and Barnaby, 1962), Koutras and Livadas (1966) have shown that $40 \mathrm{mg}$ of potassium iodide (KI) (about $30 \mathrm{mg}$ of $\mathrm{I}$ ) is the minimal single dose required completely to inhibit the uptake of tracer by the thyroid and this inhibition can be conReceived for publication 26 July 1972. tinued indefinitely by a daily intake of $3.3 \mathrm{mg}$ of potassium iodide. When it is noted that this level of iodide supplement totally inhibits tracer uptake it will be appreciated how small a supplement is required merely to depress uptake values.

Numerous iodine-containing compounds are in medical use, either as 'counter proprietaries' or by prescription. Radioopaque media have a very high iodine content : for example, a patient given Hypaque -a sodium diatrizoate/meglumine diatrizoate mixture-may receive over $8 \mathrm{~g}$ of elemental iodine. When oily media are used, an iodide depot may be formed which repletes the body iodide pool over a long period, sometimes extending to many years (Shapiro and Man, 1960; White, 1972). Thus misleading results are obtained from both proteinbound iodine (PBI) estimations and thyroid uptake studies for a similar period.

Apart from the obvious solutions and tinctures of iodine and iodized throat pastilles, a number of tonics, multivitamin and mineral compounds, and analgesic/antipyretic preparations contain iodine. TCP solution, often used as a gargle, contains $1 \cdot 1$ $\mathrm{mg} \mathrm{I} / \mathrm{ml}$, and the popular diarrhoea prophylactic, Enterovioform (clioquinol), contains over $100 \mathrm{mg} \mathrm{I}$ per tablet. This is frequently taken by travellers and a typical prophylactic course used by members of the public has been shown to have a persistent effect on the PBI and, presumptively, also on thyroid uptake test results (Sönksen, Ekins, Stevens, Williams, and Nabarro, 1968). Creams, lotions, and ointments (such as Betnovate $\mathrm{C}$ ) are frequently made up with $3 \%$ clioquinol. Even such an innocuous procedure as a cervical iodine test can inter- 
fere with both the PBI and thyroid uptake tests (Baden, Thompson, Walker, and Ardjomand, 1970).

In addition to iodine-containing medication, overloading can be of dietary origin, especially among those with unusual food habits (iodized salt and certain 'health foods' contain added iodine). Unforeseen dietary sources can also contribute to excess iodide ingestion (London, Vought, and Brown, 1965). As regards diet the propensity of food processors to add various compounds in efforts to improve their products can give rise to changes in the average dietary iodine intake of a population (Pittman, Dailey, and Beschi, 1969; Clements, Gibson, and Howeler-Coy, 1970; Connolly, 1971b).

\section{Materials and Methods}

Thyroid uptake measurements were made at four hours and 24 hours following an oral dose of 15 to $20 \mu \mathrm{Ci}$ of ${ }^{131} \mathrm{I}$ as sodium iodide (IBS 1P, Radiochemical Centre, Amersham). This rather high dose was used because thyroid scans were often required as well as serum protein-bound ${ }^{131}$ I studies 48 hours after the administration of the tracer.

The double Geiger counter system employed has been in routine use in this laboratory for many years, and although incorporating various improvements, is essentially that described by Tait, Cook, and Worsnop (1951). These authors showed that the design was such as to minimize errors caused by a patient being placed in a slightly different position for successive uptake measurements. Thus the apparatus lends itself to studies where results using it after a time lapse are compared. The standard phantom used was made here and has been shown to give results in close agreement with those obtained with the Oak Ridge Institute of Nuclear Studies' mannequin, 'Moira', and with an International Atomic Energy Agency phantom when these were each directly compared by means of our thyroid uptake equipment.

We compared the percentage uptake value recorded by Dr K. E. Jones in 1958-59 as part of an unpublished project, with uptake values recorded in 1967 when a serum $\mathrm{T} 4$ assay was being validated as a thyroid function test (Ekins, Williams, and Ellis ${ }^{\top}$ 1969), and again with similar values recorded in the last three months of 1971 and the first six months of 1972 . Such a comparison is valid because the apparatus used for the measurements and the prof cedure followed remained unchanged throughout this period.

Dr Jones had collaborated with his clinical col $\frac{\bar{\sigma}}{\bar{\sigma}}$ leagues and recorded the final diagnosis of each? patient in the earlier series, considering the resultsin of all tests carried out as well as the clinical findings $\overrightarrow{0}$ It therefore appears reasonable to assume with someconfidence that the thyroid status recorded wasw accurate. Those thus recorded as being euthyroif were selected and the four-hour and 24-hour per? centage uptake of ${ }^{131}$ I was noted. In 49 patients the uptake was recorded at both times and in $\dot{0} \vec{\circ}$ further three at 24 hours only.

For the 1967 series a lapse of at least one yeare was allowed and then the case notes of the patientso were reviewed. Particular attention was paid to the follow-up notes subsequent to the time of the tests. $O$ The response to treatment or the progress in the absence of treatment left little doubt as to the true thyroid status at the time of the tests. All thoseconsidered euthyroid were used in this study, theres being 88 for whom 24-hour uptake values woger recorded and of these 59 also had four-hour uptakes: measured. For the 1972 series advantage was taken of the referral for thyroid function screening patients with neurological disease, vascular disease obesity, etc, in whom all tests of thyroid function were normal. Of these euthyroid patients 67 had 24-hour uptake values recorded and 54 also had the uptake at four hours measured.

\section{Results}

The results are summarized in the Table. Between' 1958 and 1967 there was a significant fall in the mean thyroid uptake at both four hours and 24 hours buf between 1967 and 1972 the mean uptakes at these times did not significantly change. The changes are

\begin{tabular}{|c|c|c|c|c|}
\hline Series & Mean Uptake (\%) & $S D$ & No. of Subjects & Significance of Difference $\mathrm{P}$ \\
\hline $\begin{array}{l}\text { Four-hour Uptake } \\
1958 \\
1967\end{array}$ & $\begin{array}{l}23 \cdot 55 \\
20 \cdot 37\end{array}$ & $\begin{array}{l}7 \cdot 154 \\
6 \cdot 116\end{array}$ & $\begin{array}{l}49 \\
59\end{array}$ & .01 \\
\hline 1972 & $19 \cdot 81$ & $4 \cdot 439$ & 54 & $\mathbf{N S}$ \\
\hline $\begin{array}{l}\text { 24-hour Uptake } \\
1958 \\
1967\end{array}$ & $\begin{array}{l}38 \cdot 21 \\
31 \cdot 60\end{array}$ & $\begin{array}{l}9 \cdot 639 \\
9 \cdot 325\end{array}$ & $\begin{array}{l}52 \\
88\end{array}$ & 0.0005 \\
\hline 1972 & $31 \cdot 97$ & 6.446 & 67 & $\zeta N S$ \\
\hline
\end{tabular}

Table Analysis of the four-hour and 24-hour ${ }^{131}$ I thyroidal uptake values of euthyroid subjects in 1958-59, 1967, and 1972 
much less than those recorded by others, eg, Pittman et al (1969). On enquiry at the Ministry of Agriculture and Fisheries we were informed that the allowed additives in bread making contain neither iodides nor iodates.

\section{Discussion}

Pittman et al (1969) compared the values of the 24hour thyroidal radioiodine uptake of euthyroid subjects, selected from among the patients, medical students, and staff of the Veterans Administration Hospital, Birmingham, Alabama, in 1959 with the same index of thyroid function in similar subjects in 1967-68. The first series yielded a value of $28 \cdot 6 \pm$ $6.5 \%$ (mean \pm SD) of the administered dose while the later series yielded $15.4 \pm 6.8 \%$. Both mean values are low compared with standard 'normal' values often employed and this is considered by the authors to be due to high dietary intake of iodide. The change in the mean 24-hour uptake values appeared to be due to the introduction during the intervening years of iodine-containing additives during bread manufacture. Comparable results have been reported by Bernard, McDonald, and Nesmith (1970) and by Ghahremani, Hoffer, Oppenheim, and Gottschalk (1971). Similarly Connolly (1971a) recorded year by year falling mean values of 24-hour thyroid uptake from 1966, when iodate was added to bread, to 1970. Sachs, Siegel, Horwitt, and Siegel (1972) in comparing thyroid uptake studies in two cities have also incriminated bread as a main source of extradietary iodine affecting the results in one of the populations studied.

Our subjects were not selected from a healthy population. All three groups were composed of patients referred for thyroid investigation but in the light of the results of thyroid function studies and of clinical findings were shown to be euthyroid. It is felt that this is a more realistic means of estimating the euthyroid range of thyroid functional indices than is one dependent upon healthy volunteers because in the everyday application of thyroid function tests one is attempting to differentiate patients whose symptoms and signs are referable to thyroid dysfunction from those whose ill health mimics this.

The situation appears from our results to be rather more stable in Britain than it is in much of the United States and in some other countries and changing dietary iodine intake might here be a less important factor in modifying the normal range of thyroidal radioiodine uptake values. The significant but smaller changes noted may possibly be due to an increasing popularity of iodized medications. This conclusion is in agreement with the findings of Blum and Chandra (1971) who state that their normal range for 24-hour thyroid uptake had dropped from 20 to $45 \%$ in 1963 to 10 to $34 \%$ in 1970 but that bread could not be incriminated as a source of extra dietary iodine. They concluded, like us, that the source was probably in other items not specifically identified by them.

It is not uncommon for psychologically disturbed patients to present a difficult diagnostic problem, especially so where there is an anxiety state or agitated depression (Crown, Crisp, and Ellis, 1966). In these states the clinical findings are in many respects similar to those found in thyrotoxicosis and in a series such as ours where the final assessment indicates normal thyroid function it is probable that there will be patients who have been treated with psychotropic agents which are known to depress slightly thyroid uptake results.

This tendency for the normal range of thyroid uptake values to change with time should be noted as an additional factor in the increasing uncertainty of interpretation of tracer tests of thyroid function in vivo, the uncertainty extending also to PBI estimations. The staff of centres engaged in thyroid function studies would be well advised to keep the normal range of thyroid functional indices under review and where tests in vitro are in question to consider using alternatives such as the determination of serum T4 and of the free thyroxine index.

We are greatly indebted to Dr K. E. Jones who left such complete records that it was possible to select from them a series with which to compare the later results. We are also indebted to Miss L. I. Pope and her staff for carrying out the day-to-day work on which this study is based.

\section{References}

Acland, J. D. (1971). The interpretation of the serum protein-bound iodine: a review. J. clin. Path., 24, 187-218.

Baden, W. F., Thompson, J. Q., Walker, T. A., and Ardjomand, M. (1970). Cervical iodine test: alteration of protein-bound iodine and radioactive iodine uptake determinations. Obstet. and Gynaec. 36, 745-747.

Bernard, J. D., McDonald, R. A., and Nesmith, J. A. (1970). Low normal ranges for the radioiodine uptake study. J. nucl. $\mathrm{Med}$., 11, 449-451.

Blum, M., and Chandra, R. (1971). Lower normal values for 131-I thyroid uptake not related to the ingestion of white bread. J. nucl. Med., 12, 743-745.

Clements, F. W., Gibson, H. B., and Howeler-Coy, J. F. (1970). Goitre prophylaxis by addition of potassium iodate to bread: experience in Tasmania. Lancet, 1, 489-492.

Connolly, R. J. (1971a). Seasonal variation in thyroid function. Med. J. Aust., 1, 633-636.

Connolly, R.J.(1971b). The changing iodine environment of Tasmania . Med. J. Aust., 2, 1191-1193.

Crown, S., Crisp, A. H., and Ellis, J. P. (1966). Some aspects of the diagnosis of thyrotoxicosis. J. Psychosomat. Res., 10, 209-214.

Ekins, R. P., Williams, E. S., and Ellis, S. M. (1969). The sensitive and precise measurement of serum thyroxine by saturation analysis (competitive protein binding assay). Clin. Biochem., 2, 253-288. 
Forcher, H. M., Lanaro, A. E., Enriori, C. L., and Reforzo-Membrives, J. (1971). Adaptation of thyroid function to iodine intake in Buenos Aires. J. clin. Endocr., 32, 254-259.

Ghahremani, G. G., Hoffer, P. B., Oppenheim, B. E., and Gottschalk, A. (1971). New normal values for thyroid uptake of radioactive iodine. J. Amer. med. Ass., 217, 337-339.

Koutras, D. A., and Livadas, D. (1966). The minimum dose of potassium iodide which inhibits the thyroidal radioiodine uptake. Nuclearmedizin, 5, 256-261.

London, W. T., Vought, R. L., and Brown, F. A. (1965). Breada dietary source of large quantities of iodine. New Engl. $J$. Med., 273, 381.

Oddie, T. H., and Fisher, D. A. (1967). Mean euthyroid 24-hour radioiodine uptake as a characteristic of different patient populations. J. clin. Endocr., 27, 11-14.

Pittman, J. A., Jr., Dailey, G. E., III, and Beschi, R. J. (1969). Changing normal values for thyroidal radioiodine uptake. New Engl. J. Med., 280, 1431-1434.
Pochin, E. E., and Barnaby, C. F. (1962). The effect of pharmacological doses of non-radioactive iodine on the course of radio- $\square$ iodine uptake by the thyroid. Hlth Phys., 7, 125-126.

Sachs, B. A., Siegel, E., Horwitt, B. N., and Siegel, E. (1972). Bread iodine content and thyroid radioiodine uptake: a tale of two으. cities. Brit. med. J., 1, 79-81.

Shapiro, R., and Man, E. B. (1960). Iophenoxic acid and serumbound iodine values. J. Amer. med. Ass., 173, 1352.

Sönksen, P. H., Ekins, R. P., Stevens, H. G., Williams, E. S., and? Nabarro, J. D. N. (1968). Serum-levels of protein-bound $\bar{O}$ iodine and thyroxine after a course of clioquinol. Lancet, $2, \overline{\bar{S}}$ 425-426.

Tait, J. F., Cook, J. R., and Worsnop, R. (1951). Physical Measure- $\mathbb{D}$ ments in routine clinical diagnosis with $\mathrm{I}^{131}$. Brit. J. Radiol., 24, 14-16.

White, G. W. (1972). Prolonged elevation of serum protein-bound $\overrightarrow{-}$ iodine following myelography with Myodil. Brit. J. Radiol... 45, 21-23.

\section{Reports and Bulletins prepared by the Association of Clinical Biochemistso}

The following reports and bulletins are published by the Association of Clinical Biochemists. They may be obtained ${ }^{\text {ㄱ․ }}$ from The Administrative Office, Association of Clinical Biochemists, 7 Warwick Court, Holborn, London, WC1R 5DP. The prices include postage, but air mail will be charged extra. Overseas readers should remit by British Postal or Money Order. If this is not possible the equivalent of 50p is the minimum amount that can be accepted.

SCIENTIFIC REPORTS

3 Automatic Dispensing Pipettes. An assessment of 35 commercial instruments 1967 P. M. G. BROUGHTON, A. H. GOWENLOCK, G. M. WIDDOWSON, and K. A. AHLQUIST 85p (\$2)

4 An Evaluation of five Commercial Flame Photometers suitable for the Simultaneous Determination of Sodium and Potassium March 1970 P. M. G. BROUGHTON and J. B. DAWSON $85 p(\$ 2)$

SCIENTIFIC REVIEWS

1 The Assessment of Thyroid Function March 1971 F. V. FLYNN and J. R. HOBBS $62 \mathrm{t} p(\$ 1.50)$

2 Renal Function Tests Suitable for Clinical Practice January 1972 F. L. MITCHELL, N. VEALL, and R. W. E. WATTS $62 \frac{1}{2} \mathrm{p}(\$ 1.50)$

\section{TECHNICAL BULLETINS}

9 Determination of Urea by AutoAnalyzer November

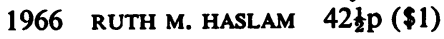

11 Determination of Serum Albumin by AutoAnalyzer using Bromocresol Green October 1967 B. E. NORTHAM

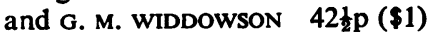

13 An Assessment of the Technicon Type II Sampler Unit March 1968 B. C. GRAY and G. K. MCGOWAN $42 \frac{1}{2} \mathrm{p}(\$ 1)$

14 Atomic Absorption Spectroscopy. An outline of its principles and a guide to the selection of instruments May 1968 J. B. DAWSON and P. M. G. BROUGHTON $42 \frac{1}{2} p(\$ 1)$
15 A Guide to Automatic Pipettes (2nd edition)

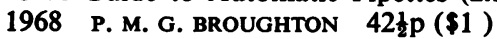

16 A Guide to Automation in Clinical Chemistry

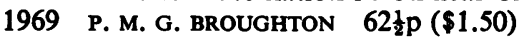

17 Flame Photometers (2nd edition) 1969 $62 \frac{1}{2} \mathrm{p}(\$ 1.50)$

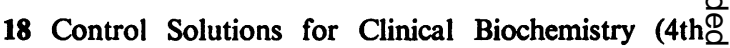
edition) March 1970 P. M. G. BROUGHTON $62 \frac{1}{2} \mathrm{p} \underset{\vec{F}}{\vec{F}}$ (\$1.50)

19 Spectrophotometers. A comparative list of low-priced instruments readily available in Britain May 1970 C. E. WILDE and P. SEWELL 62tp (\$1.50)

20 Quantities and Units in Clinical Biochemistry June 1970 P. M. G. BROUGHTON $62 \frac{1}{2} p(\$ 1.50)$ More than 30 copies in units of 10 at 20p

21 Filter Fluorimeters: A comparative list of 18 instruments September 1970 H. BRAUNSBERG and s. S. BROWN $62 \frac{1}{2} \mathrm{p}(\$ 1.50)$

22 Bilirubin standards and the Determination of Bilirubino by Manual and Technicon AutoAnalyzer Methods January 1971 BARBARA BILLING, RUTH HASLAM, and N. WALD $62 \frac{1}{2} \mathrm{p}(\$ 1.50)$

23 Interchangeable Cells for Spectrophotometers and N Fluorimeters September 1971 E. S. BROWN and A. 11.0 GOWENLOCK $62 \frac{1}{2} \mathrm{p}(\$ 1.50)$

24 Simple Tests to Detect Poisons March 1972 B. w. MEADE et al. $\quad 62 \frac{1}{2} \mathrm{p}(\$ 1.50)$

25 Blood Gas Analysers May 1972 K. DixoN 62 $\frac{1}{2} \mathrm{p}$ $(\$ 1.50)$ 